\title{
PREVALENCE OF ERUPTED SUPERNUMERARY TEETH AND ASSOCIATED ORAL COMPLICATIONS AMONG A GROUP OF EGYPTIAN CHILDREN : A CROSS SECTIONAL STUDY
}

\author{
Riham Ahmed El-Halafawey*, Randa Youssed AbdEl-gawad** \\ and Rasha Mohamed Hatem Hanafy***
}

\begin{abstract}
Background: Hyperdontia is one of the most prevalent dental anomalies that affect primary or permanent dentition. It is any tooth or tooth like structure that can be found anywhere in the dental arches and may causes various orofacial complications. Early detection and treatment of supernumeraries prevent possible future complications.
\end{abstract}

Aim: assess the prevalence and the associated complications of erupted supernumerary teeth among a group of Egyptian children.

Methodology: Patients who fulfilled the eligibility criteria were recruited from the Outpatients' clinic of Pediatric Dentistry and Dental Public Health Department, Faculty of Dentistry, Cairo University. Children were examined clinically for the prevalence of erupted supernumeraries taking into consideration their type, location, shape and the associated complications.

Results: Out of the examined 604 patients, only 13 patients (2\%) were diagnosed with hyperdontia, their ages ranged between 6 and 15 years old (mean age $=8.5$ years old), with male: female ratio equals $=1.6: 1$. Out of the examined supernumeraries, 9 teeth $(69 \%)$ were mesiodentes causing (19 oral complications) and 4 teeth (31\%) were supplemental teeth causing 3 dental complications and 1 supplemental tooth with no specific complication. Gingivitis was the most common complication associated with erupted mesiodentes and crowding of dental arches was the most common complication caused by supplemental teeth.

Conclusion: The prevalence of hyperdontia was $2 \%$ and complications were associated with all of the diagnosed mesiodentes and gingivitis was the most common one. While the majority of the found supplemental teeth caused crowding and the remaining had no specific complications.

Background: Hyperdontia is one of the most prevalent dental anomalies that can affect primary or permanent dentition. It is any tooth or tooth like structure that can be found anywhere in one or both dental arches and most of time it causes various orofacial complications. Early detection and treatment of supernumeraries prevent possible future complications.

KEYWORDS: supernumerary teeth; hyperdontia; accessory teeth; mesiodens; paramolar; distomolar.

* B.D.S, Faculty of Dentistry, Cairo University, 2011.

** Associate Professor of Pediatric Dentistry and Dental Public Health, Faculty of Dentistry, Cairo University.

*** Lecturer of Pediatric Dentistry and Dental Public Health, Faculty of Dentistry, Cairo University. 


\section{INTRODUCTION}

Dental anomalies are deviations from the normal tooth form, number, function or position. They are usually due to developmental or metabolic disturbance leading to alteration in the normal color, shape, size, number, or degree of development of teeth. ${ }^{(1)}$ Anomalies in the normal number of teeth include either supernumerary teeth (hyperdontia) or hypodontia (decrease in the number of teeth from normal compliment). ${ }^{(2)}$

Supernumerary tooth is any tooth extra than the normal number of teeth in both of primary and/ or permanent dentitions. It is five times more frequent in permanent dentition than in primary one. It can be found anywhere in the jaws with higher frequency in the anterior region of the maxilla. Its prevalence in males is two times more than in females. ${ }^{(3)}$

Supernumerary teeth can be categorized according to their location and their morphology. Regarding the location, they are classified to: mesiodens, paramolar or distomolar. ${ }^{(4)}$ Supernumerary teeth are classified according to their shape into: «Supplemental teeth"; which resemble the adjacent teeth with normal anatomy and morphology and «dysmorphic type»; which are teeth of anomalous size and shape. ${ }^{(5)}$

Many theories were postulated concerning the cause of hyperdontia such as (atavism theory, dichotomy, hyperactivity of dental lamina theory, genetic factors, hereditary). Despite of all these theories, the exact etiology of supernumerary teeth is still unknown. However, alterations during odontogenesis are believed to be causative factors of the appearance of extra teeth. ${ }^{(6)}$

Supernumerary teeth can be asymptomatic causing no problems and discovered accidentally while routine course of radiographic examination. However, most of them cause a variety of odontogenic and maxillofacial problems including: crowding, delayed eruption, spacing, impaction of perma- nent incisors, retained primary teeth, abnormal root formation, median diastema, cystic lesions, intraoral infection, rotation, root resorption of the adjacent teeth, or even eruption of incisors in the nasal cavity. ${ }^{(7)}$

\section{SUBJECTS AND METHODS}

- Study design: This study is an observational cross-sectional study.

- Sample size determination: sample size was calculated to be 604 patients, and approved by Medical Biostatistics Unit- faculty of DentistryCairo University. It was calculated based on the previous research of Singh et al. (2014) ${ }^{(8)}$.

The equation used in sample size determination: $n=z 2 p q / d 2$

where $\mathrm{Z}$ is the ordinate on the Normal curve corresponding to the alpha level

$\mathrm{P}$ : assumed proportion

$\mathrm{q}=1-\mathrm{p}$

$\mathrm{d}:$ difference margin

Input : prevalence 1.6 (Singh et al., 2014). Assumed difference margin $1 \%$ (expected range $0.6 \%-3.2 \%$ ).

Confidence level : $95 \%$.

Power of the study : $80 \%$.

- Ethics approval: The study was reviewed and approved by the Dental Research Ethics Committee, Faculty of Dentistry, Cairo University.

\section{- Study registration:}

» The study was registered on clinical trial website, http:www.clinicaltrial.com.gov, with protocole ID: remam, clinical trial.gov ID: NCT03650634 and was verified on August 2018.

" The research was approved by EvidenceBased Committee, Faculty of Dentistry, Cairo University on $25^{\text {th }}$ December 2018.

» The research was approved by department board on $1^{\text {st }}$ of January 2019. 
- Participants: Children were recruited from the Out patients' clinic of Pediatric Dentistry and Dental Public Health Department, Faculty of Dentistry, Cairo University, Egypt.

\section{Subjects were selected according to the following eligibility criteria}

\section{a)-Inclusion criteria:}

1. Medically free children, aged from 6-15 years old.

2. Both genders were included

3. Co-operative patient and parent acceptance for participation in the study.

\section{b)-Exclusion criteria:}

1- Any genetic disorder.

- Informed consent: Prior to clinical examination, the purpose and the procedure of the study were explained in details to the patients and their care-givers. Verbal assent was obtained from the children while a written consent was obtained from their care-givers.

\section{Working Procedures}

- Children attended the Outpatients' clinic on the days of examination were primary screened and those who fulfilled the eligibility criteria were included in the study sample.

- Personal data, medical and dental history were recorded for each patient in a custom-made examination chart, filled through an oral-interview and clinical examination for all children.

\section{Clinical examination}

Patients were seated on the dental chair ${ }^{1}$ and clinical examination was done under the dental unit light source using disposable diagnostic set ${ }^{2}$. Patients were evaluated carefully for the presence of erupted supernumerary teeth and the existed associated complications. Obtained data were recorded in a custom-made examination chart and photographs were taken for all cases.

\section{Statistical analysis:}

Statistical analysis was performed using SPSS ${ }^{\circledR * * *}$ version 24 , descriptive statistics were presented as mean scores, standard deviation (SD) and frequency distribution. The categorial data including the prevalence were described as number and percentage.

\section{RESULTS}

A total of 604 patients were examined during the period from April to September 2019. Out of the examined 604 patients, 13 (2\%) children had supernumerary teeth in their dentitions; their ages were between 6 and 15 years old with a mean age of 8.5 years old and a male: female ratio equal to 1.6:1. All of the 13 patients were evaluated clinically only for the associated oral and dental complications due to their extra teeth. Out of the 13 erupted supernumeraries; 9 (69\%) were mesiodentes and 4 $(31 \%)$ were supplemental teeth.

TABLE (1) : Prevalence of erupted supernumerary teeth among the whole study sample:

\begin{tabular}{|c|c|c|}
\hline $\begin{array}{c}\text { Total number } \\
\text { of examined } \\
\text { population }\end{array}$ & \multicolumn{2}{|c|}{$\begin{array}{c}\text { Number of patients with erupted } \\
\text { supernumerary teeth }\end{array}$} \\
\hline \multirow{2}{*}{604} & $\begin{array}{c}|c| \\
\text { Number of patients } \\
\text { had erupted } \\
\text { mesiodentes }\end{array}$ & $\begin{array}{c}\text { Number of patients } \\
\text { had erupted } \\
\text { supplemental teeth }\end{array}$ \\
\cline { 2 - 3 } & $9(69 \%)$ & $4(31 \%)$ \\
\cline { 2 - 3 } & & \\
\hline
\end{tabular}

\footnotetext{
* Knight ${ }^{\circledR}$ dental chair by Midmark, American global manufacturer of healthcare products, Ohio, U.S.A.

** Kandil@ disposable diagnostic set.

*** Statistics software developed by IBM ${ }^{\circ}$, American multinational information technology company, New York, U.S.A.
} 


\section{Mesiodens}

TABLE (2): Oral and dental complications caused by erupted mesiodentes:

\begin{tabular}{|l|c|}
\hline The associated complication & Number of the causative supernumerary teeth \\
\hline Gingivitis & 4 \\
\hline Rotation of the adjacent teeth & 3 \\
\hline Crowding & 3 \\
\hline Midline diastema & 2 \\
\hline Displacement of the adjacent teeth & 2 \\
\hline Speech difficulty & 1 \\
\hline Delayed eruption of the permanent incisor & 1 \\
\hline Premature shedding of the primary incisor & \multicolumn{2}{|c|}{} \\
\hline
\end{tabular}

The 9 mesiodentes caused 19 oral and dental complications and the gingivitis was the most prevalent complication.

TABLE (3): Distribution of complications caused by erupted mesiodentes according to their morphology.

\begin{tabular}{|c|c|c|c|c|c|c|c|c|}
\hline Complications & Gingivitis & Crowding & $\begin{array}{c}\text { Midline } \\
\text { diastema }\end{array}$ & $\begin{array}{c}\text { Rotation of } \\
\text { the adjacent } \\
\text { teeth }\end{array}$ & $\begin{array}{c}\text { Displacement } \\
\text { of the adja- } \\
\text { cent teeth }\end{array}$ & $\begin{array}{c}\text { Speech } \\
\text { difficulty }\end{array}$ & $\begin{array}{c}\text { Premature } \\
\text { shedding of } \\
\text { the primary } \\
\text { mcisor }\end{array}$ & $\begin{array}{c}\text { Delayed erup- } \\
\text { tion of the } \\
\text { permanent } \\
\text { mcrsor }\end{array}$ \\
\hline $\begin{array}{c}\text { Conical } \\
\text { (4 teeth) }\end{array}$ & 2 & 1 & 1 & 0 & 1 & 1 & 0 & 1 \\
\hline $\begin{array}{c}\text { Tuberculate } \\
(2 \text { teeth) }\end{array}$ & 1 & 1 & 1 & 2 & 0 & 0 & 0 & 0 \\
\hline $\begin{array}{c}\text { Molariform } \\
\text { (2 teeth) }\end{array}$ & 1 & 1 & 1 & 1 & 0 & 0 & 1 & 0 \\
\hline $\begin{array}{c}\text { Incisiform with } \\
\text { notch } \\
(1 \text { tooth })\end{array}$ & 0 & 0 & 0 & 0 & 1 & 1 & 0 & 0 \\
\hline
\end{tabular}

TABLE (4): Distribution of complications caused by erupted mesiodentes according to their location.

\begin{tabular}{|c|c|c|c|c|c|c|c|c|}
\hline morpholo & Gingivitis & Crowding & $\begin{array}{l}\text { Midline } \\
\text { diastema }\end{array}$ & $\begin{array}{l}\text { Rotation of } \\
\text { the adjacent } \\
\text { teeth }\end{array}$ & $\begin{array}{l}\text { Displacement } \\
\text { of the adj cent } \\
\text { teeth }\end{array}$ & $\begin{array}{l}\text { Speech } \\
\text { difficulty }\end{array}$ & $\begin{array}{l}\text { Premature } \\
\text { shedding of } \\
\text { the primary } \\
\text { incisor }\end{array}$ & $\begin{array}{l}\text { Delayed } \\
\text { eruption of } \\
\text { the perma- } \\
\text { nent incisor }\end{array}$ \\
\hline $\begin{array}{c}\text { Midline between } \\
\text { the two incisors at } \\
\text { the line of occlusion } \\
\text { ( } 3 \text { teeth) }\end{array}$ & 1 & 2 & 3 & 2 & 1 & 0 & 0 & 0 \\
\hline $\begin{array}{l}\text { Between the two } \\
\text { incisors palatally } \\
\text { (1 tooth) }\end{array}$ & 1 & 1 & 0 & 1 & 0 & 0 & 0 & 0 \\
\hline $\begin{array}{l}\text { Behind one of the two } \\
\text { incisor ( } 3 \text { teeth) }\end{array}$ & 1 & 0 & 0 & 0 & 1 & 2 & 0 & 0 \\
\hline $\begin{array}{l}\text { At the place of one of } \\
\text { the incisors ( } 2 \text { teeth) }\end{array}$ & 1 & 0 & 0 & 0 & 0 & 0 & 1 & 1 \\
\hline
\end{tabular}


Presence of supernumeraries in the midline between the two central incisors at the line of occlusion is the most common location associated with complications as 3 teeth caused a total of 9 complications.

\section{Supplemental teeth}

TABLE (5): Complications associated with erupted supplemental teeth:

\begin{tabular}{|c|c|c|}
\hline $\begin{array}{c}\text { The existed } \\
\text { complication }\end{array}$ & $\begin{array}{c}\text { Number of } \\
\text { supplemental teeth }\end{array}$ & $\begin{array}{c}\text { Percentage of } \\
\text { supplemental teeth }\end{array}$ \\
\hline Crowding & 3 & $75 \%$ \\
\hline $\begin{array}{c}\text { No specific } \\
\text { complication }\end{array}$ & 1 & $25 \%$ \\
\hline
\end{tabular}

\section{DISCUSSION}

Hyperdontia is one of the widely reported and significant anomalies that can be found in both primary and permanent dentitions and leads to a lot of complications. ${ }^{(9)}$

The assessment of supernumerary teeth and the associated orofacial complications helps in preventing possible future problems and increases the awareness of pediatric dentists, the parents and the community about hyperdontia and the possible harmful effect that may occur due to the presence of extra teeth. It also reflects light about the importance of seeking early treatment and the role of pedodontists in early detection and treatment. ${ }^{(1)}$

The current study design was an observational cross sectional, as it is considered the most suitable design in reporting diseases or anomalies in populations. ${ }^{(10)}$ This goes in accordance with most of the designs of studies done to assess hyperdontia and associated phenomena. ${ }^{(11-15)}$

All patients in the present study were evaluated clinically only, for the presence and the complications of erupted supernumerary teeth and no radiographic examination was done, as recommended by the department board, to avoid unnecessary radiation exposure to children especially those who are asymptomatic. This goes in accordance with Alberti et al., (2006) in Italy ${ }^{(16)}$; Miyoshi et al., (2008) in Japan ${ }^{(17)}$; Kramer et al., (2008) in Brazil (11); Khandelwal et al., (2011) in Indore, India (13); Mahabob et al., (2012) in South India ${ }^{(12)}$; and Singh et al., (2019) in Malaysia ${ }^{(15)}$ who applied the same method for assessment of supernumerary teeth but disagrees with Padro et al., (2009) in Barecelona ${ }^{(18)}$; Vahid et al., (2011) in Iran ${ }^{(19)}$; McBeain and Miloro (2018) in Chicago ${ }^{(14)}$ and Bello et al., (2019) in Nigeria ${ }^{(20)}$ as supernumeraries may be impacted in the oral cavity which may lead to misinterpretation of some complications.

In the present study, the male: female ratio was (1.6:1). This goes in accordance with male dominance that was reported in the majority of studies done on different populations all over the world, but with different male: female ratios. This male dominance may be explained by the theory which postulates that supernumerary teeth is a sex-linked anomaly associated with X- chromosome. ${ }^{(19,21-23)} \mathrm{On}$ the other hand, the male/ female ratio in this study disagreed with one study carried out in Turkey by Durmuslar et al., (2015) (24), where females were more affected than males with a ratio of (1.3:1).

Regarding the type of supernumerary teeth found in this study, (69\%) were mesiodentes and (31\%) were supplemental teeth, no paramolars or distomolars were found among the study population, Similarly, Gupta and Kumar (2017) ${ }^{(25)}$ classified the type of the teeth he had found and the mesiodentes were the most prevalent type with a percentage of (93.6\%) of all the found extra teeth, followed by supplemental teeth $(6.4 \%)$. However, Khandelwal et al. (2018) ${ }^{(26)}$ reported different results as the most prevalent type was the parapremolars (39.02\%) followed by mesiodens (21.95\%), then paramolars (20.73\%), the forth prevalent type was distomolar $(10.98 \%)$ and the least type was supplemental $(7.32 \%)$. This difference may be due to the age group of the present study which recruited younger patients compared to other studies as it was reported 
that supernumerary paramolars and parapremolars develop at a later stage during adulthood. ${ }^{(20,24,27)}$

Regarding the complications; the complications were assessed separately for both of the mesiodentes and supplemental teeth. The most common complication associated with mesiodentes was gingivitis $(21.5 \%)$, then; three complications (rotation of adjacent teeth, crowding, crowding and midline diastema ) recorded the same prevalence ratio which was $(15.8 \%)$, while the third prevalent complication was displacement of adjacent teeth and speech difficulty as both of them recorded the same prevalence percentage which was $(10.5 \%)$ and finally, both of early shedding of primary incisor and delayed eruption of permanent incisors recorded the least presence percentage which was $(5.2 \%)$.

Regarding the supplemental teeth; (75\%) of the supplemental teeth were associated with crowding, while $(25 \%)$ had no specific complication.

These results disagreed with Durmuslar et al., (2015) ${ }^{(24)}$ who revealed that approximately $(67.3 \%)$ of the found supernumerary teeth were asymptomatic causing no complications, $(18.6 \%)$ caused delayed eruption of the permanent teeth, (5.1\%) caused displacement of the adjacent teeth and (9\%) were associated with a pathology and Syriac et al., (2017) ${ }^{(22)}$ who reported that about $(37.8 \%)$ of the supernumeraries caused rotation of the adjacent teeth, $(24.2 \%)$ caused delayed eruption of the neighboring teeth, $(22.2 \%)$ caused median diastema and $(15.5 \%)$ caused no problem.

\section{CONCLUSION}

From the results of this study we concluded that supernumerary teeth are dental anomalies which are most of time accompanied with various and multiple oral complications. The prevalence of erupted supernumerary among Egyptian children is relatively high (2\%). Gingivitis is the most common complication followed by crowding, midline diastema and rotation of adjacent teeth, while premature shedding of primary incisor and delayed eruption of the permanent incisors were the least prevalent complications associated with erupted mesiodentes. Seventy five percent of the supplemental teeth caused crowding in the dental arch while $25 \%$ had no specific complications.

The results of our study reflects the light about the importance of early treatment of supernumeraries in order to prevent the complications which may happen.

\section{REFERENCES}

1. Patil, S.; Doni, B.; Kaswan, S. and Rahman, F. (2013): Prevalence of dental anomalies in indian population. J Clin Exp Dent., 5 : 183-186.

2. Guttal, K.; Naikmasur, V.; Bhargava, P. and Bathi, R. (2010): Frequency of developmental dental anomalies in the Indian population. Eur J Dent., 4: 263-266.

3. Srinivasan, K. and Chrita, S. (2015):Mystery behind hyperdontia: report of two cases. Int J Appl Dent., 1: 05-09.

4. Cassetta, M.; Altieri, F.; Giansanti, M.; Di-Giorgio, R. and Calasso, S. (2014): Morphological and topographical characteristics of posterior supernumerary molar teeth: An epidemiological study on 25,186 Subjects. Med Oral Patol Oral Cir., 19: 545-549.

5. Paradowska, A. and Nowakowska, A. (2014): Literature review on supernumerary teeth. Dent Med Probl., 51: 513-517.

6. Shih, W.; Hsieh, C. and Tsai, T. (2016): Clinical evaluation of the timing of mesiodens removal. JCMA; $79: 345-350$.

7. Duraisingam, S.; Rajalakshmi, R. and Rameshkumar, K. (2014):Supernumerary teeth - an overview of location, diagnosis and management. Res J Pharm Biol Chem Sci., 5: 1919-1924.

8. Singh, V.; Sharma, A. and Sharma, S. (2014):Supernumerary teeth in Nepalese children. Scientific World J; 2014: Article ID: 215396,5 pages.

9. Itaya, S.; Oka, k.; Kagawa, T.; Oosaka, Y.; Ishii, K.; Kato, Y.; Baba, A. and Ozaki, M. (2016): Diagnosis and management of mesiodens based on the investigation of its position using cone-beam computed tomography. Pediatr Dent J., 26: 60-66.

10. Munnangi, S. and Boktor, S. (2019): Epidemiology Of Study Design. StarPearls (Internet)., Article ID: NBK470342. 
11. Kramer, P.; Feldens, C.; Ferreira, S.; Spiguel, M. and Feldens, E. (2008):Dental anomalies and associated factors in 2- to 5-year-old Brazilian children. Int J Paed Dent., 18: 434-440.

12. Mahabob, M.; Anbuselvan, G.; Kumar, B.; Raja, S. and Kothari, S. (2012): Prevalence rate of supernumerary teeth among non-syndromic south Indian population: An analysis. J Pharm Bioall Sci., 4: 373-375.

13. Khandelwal, V.; Naveen, R.; Nayak, P.; Nayak,A.; Ninawe, N. and Prasad, S. (2011): Prevalence of mesiodens among six- to seventeen-year-old school going children of Indore. J Ind Soc Pedod Prev Dent., 29: 288-293.

14. McBeain, M. and Miloro, M. (2018): Characteristics of supernumerary teeth in nonsyndromic population in an urban dental school setting. J Oral Maxillofac Surg., 76:933-938.

15. Singh, S.; Gupta, k.; Kumaresan, R.; Pendalya, S. and Kondreddy, K. (2019): Prevalence of supernumerary teeth in non-syndromic Northern Malaysian population. EAS J Dent Oral Med., 1: 58-61

16. Alberti, G.; Mondani, P. and Parodi, V. (2006): Eruption of supernumerary permanent teeth in a sample of urban primary school population in Genoa, Italy. Eur J Paediatr Dent., 7: 89-92.

17. Miyoshi, S.; Tanaka, S.; Kunimatsu, H.; Murakami, Y.; Fukami, M. and Fujisawa, S. (2008): An epidemiological study of supernumerary primary teeth in Japanese children: A review of racial differences in the prevalence. Oral Dis., 6 : 99-102.

18. Padro, E.; Armengol, J. and Amat, E. (2009): A descriptive study of 113 unerupted supernumerary teeth in 79 pediatric patients in Barcelona. MED ORAL PATOL ORAL., 14: 46-52.

19. Vahid, E.; Farahani, A.; Mahdian, M. and Amini, N. (2011): Supernumerary teeth amongst Iranian orthodontic patients. a retrospective radiographic and clinical survey. Acta. Odontol. Scand., 69: 125-128.

20. Bello, S.; Olatunbosun, W.; Adeoye, J.; Adebayo, A. and Ikimi, N. (2019): Prevalence and presentation of hyperdontia in a non-syndromic, mixed Nigerian population. J Clin Exp Dent., 11: 930-936.

21. Anthonappa, R.; King, N. and Rabie, A. (2013): Aetiology of supernumerary teeth: A literature review. EAPD., 14: 279-288.

22. Syriac, G.; Joseph, E.; Rupesh, S.; Philip, J.; Cherian, S. and Mathew, J. (2017):Prevalence, characteristics, and complications of supernumerary teeth in nonsyndromic pediatric population of South India: A clinical and radiographic study. J

23. Gamze, A.; Erdem, A.; Onur, O. and Gulsum, A. (2019): The prevelance of mesiodens in a group of non-syndromic Turkish children: A radiographic study. Eur Oral Res; 52: 162-166.

24. Durmuslar, M.; Misir, A. and Demiriz, L. (2015): Prevalence and characteristics of supernumerary teeth: A survey on 7348 people. J Int Soc Prev Community Dent., 5: 39-43.

25. Gupta, S. and Kumar, P. (2017): A study on prevalence, complications, and possible etiologic factors of supernumerary teeth in 6-12-years old schoolchildren of Rohtak, India. Indian J Dent Sci., 9: 141-147.

26. Khandelwal, P.; Rai, A.; Bulgannawar, B.; Hajira, N.; Masih, A. and Jyani, A. (2018): Prevalence, characteristics, and morphology of supernumerary teeth among patients visiting a dental institution in Rajasthan. Contemp Clin Dent., 9: 349-356.

27. Alhashimi, N.; Al Jawad, F.; Al Sheeb, M.; Al Emadi, B.; Abdulla, J. and Al Yafei, H. (2016): The prevalence and distribution of nonsyndromic hyperdontia in a group of Qatari orthodontic and pediatric patients. Eur J Dent., 10: 392-96. 